\title{
Selected Posters
}

Profitability of Different Biological Types of Beef Cattle Developed under a Rotational Management-Intensive Grazing System. Arbindra P. Rimal, Tommy Perkins, Southwest Missouri State University; and Michelle Thomas, Hayden Brown, and Wayne Kellogs, University of Arkansas.

Rotational management-intensive grazing (RMIG) helps provide animals nutrient-dense forages to meet nutritional requirements of ruminants. Cattle raised on pasture may result in lower feed costs and also fetch premium price as it can be targeted to consumers who prefer pasture-based beef instead of grain-fed beef. Commercial beef steers approximately 9 to 12 months of age $(n=33)$ representing four biological types were evaluated for muscle and fat deposition using carcass traits. Preliminary results showed that large frame, late maturing cattle (LL) generated the largest amount of gross profit per animal followed by medium frame, late maturing (ML), and medium frame, intermediate maturing (MI).

Cotton Producers-Past, Present, and Future. Blake Brown, North Carolina State University; George Frisvold, University of Arizona; Ken Paxton, Louisiana State University; and Jeanne Reeves, Cotton Incorporated.

The Census of Agriculture data were used to determine the status of U.S. Cotton Producers. The Census assigns farms to commodity groups based on the commodity accounting for the largest share of income. Recompiled data represented all farms with cotton income. Study variables included income, labor, gross returns, land tenure, yield, farm size, farm occupants, crops grown, and irrigation. Impacts on the national economy include commodity sales, dollars spent on labor, farm type, and land tenure arrangements. One implication for outreach and technology transfer is that the cotton industry is diverse, including many producers whose primary commodity is not cotton.

Assessing the Linkages among United States and Chicken Export Prices: A TimeSeries Approach. Harjanto Djunaidi, Middle Tennessee State University.

Within a one-year forecast horizon, export price is affected by its lagged prices and broiler farm prices in Alabama and Arkansas. White meat price does not have as significant an impact on export price as dark meat price. Export price is exogenous after a one-year forecast horizon, accounting for $40 \%$ of its own variation. Within a one-year forecast horizon, $\mathrm{BSB}$ is affected by its own price and the price in Alabama. Farm price in Alabama has strong relationships to export price, U.S. white meat price, and the price of wings, suggesting it plays an important role in price transmission to other markets.

A Case Study Analysis of Precision Farming Practices. Steven W. Martin and Swagata Banerjee, Mississippi State University; and James Hanks, USDA-ARS Jamie Whitten Agricultural Research Center.

Precision farming technologies are becoming increasingly popular. Few studies have addressed the whole farm and fixed expense of these technologies. A 33-acre farm example is used to establish baseline cost estimates of these technologies. Where possible, any benefits derived from the precision farming practices were also captured by estimating yield differences and associated net revenue gains. Findings suggest that per-acre expense is relatively small if sufficient acres are available. Future efforts possibly should be made to "re- 
arrange" the precision farming input levels in an effort to maximize net revenue per zone.

Marketing Channels and Contracts Used by Argentine Soybean Producers. Matias $\boldsymbol{G}$. Nardi and Todd D. Davis, Clemson University; and Hugo A. Cetrangolo, Unidad de Agronegocios $e$ Industria Alimenticia, Universidad de San Andres, Buenos Aires, Argentina.

Soybean first-handlers in Argentina elevators, cooperatives, crushers, and exporters were surveyed to determine soybean market risk management by producers. The shares of each marketing channel were: producer-elevator $(65 \%)$; producer-cooperatives $(24 \%)$; producer-industry (7\%); and, producer-exporter $(4 \%)$. The marketing contracts used by soybean producers ranked as follows: cash on delivery-sell from storage, delayed pricing contracts, forward contracts, and exchange operations. Given that the producer in Argentina has historically received less government support and protection, knowledge of market risk management practices used in Argentina provides better understanding of the risk management tools without government programs distorting the market.

Is Conservation Tillage an Economically Warranted Production Strategy under the 2002 Peanut Program: A Perspective of Southern Peanut Production. Nathan $B$. Smith, Stanley M. Fletcher, and John Baldwin, University of Georgia; and Vijay Subramaniam, University of Kentucky.

Research and interest in conservation tillage for peanuts is growing in Southern peanutproducing states. Planting peanuts in twin-row patterns has been shown to increase yields and economic returns. This poster presents results of an economic analysis of strip tillage peanut research for single and twin-row patterns. The results show switching to twin-row pattern or strip tillage increases net returns to management but the benefits are not necessarily additive. An investment analysis is conducted to determine if switching to strip tillage is eco- nomically feasible for Southern peanut producers.

Profitability of Soybean Seed Treatments. Paul Scott Poag and Michael Popp, University of Arkansas.

A soybean seed treatment study was used to determine effects of location, seeding rate, simulated flooding at emergence, planting month, and seed quality. Changes in stand count allowed estimation of economically optimal seeding rates and in turn partial returns (PR equals gross revenue minus seed cost). Allegiance had the highest average $P R$ at $\$ 217.56 /$ acre. Untreated seed, by comparison, exhibited PR that were $\sim \$ 13 /$ acre less on average. Using high- rather than low-quality seed treated with Allegiance always improved PR (avg. of \$23/acre). May plantings provided better yields compared with April and June. Finally, as the planting season progresses, replanting thresholds decreased.

The Impact of Agriculture on the Arkansas Economy. Jennie Popp, Gina Vickery, H. L. Goodwin, and Wayne Miller, University of Arkansas.

An analysis of the impact of agriculture in Arkansas has found that agriculture is responsible for more than $20 \%$ of jobs, $15 \%$ of income, and $20 \%$ of value added. Much of the impacts generated by agriculture accrue to other sectors of the economy, such as wholesale and retail trade, financial/real estate services, and health services. Continued strength of agriculture is of paramount importance if the social and economic fabric of rural Arkansas communities is to be retained, and if the essential infrastructure and services that translate into an acceptable quality of life for its residents are to be maintained.

Maturity Group Effects on Optimal Soybean Seeding Rates and Reseeding Thresholds. Michael Popp, Patrick Manning, and Larry Purcell, University of Arkansas; and Jeffrey Edwards, Oklahoma State University. 
Analysis of seeding rates for MG 00 (short season) to VI (long season) soybean revealed that MG II and higher exhibited partial returns (above seed and irrigation costs) in excess of $\$ 206 / a c$. The study revealed substantially different investment in seed $(\$ 39 / \mathrm{ac}$ for MG 00 to $\$ 10 / a c$ for MG VI), which implied that replanting risk increased with a shorter production season. Later-maturing soybean also exhibited greater flexibility with respect to lesser-than-expected seedling establishment as yield response to stand count is less pronounced compared with earlier maturing cultivars. Lower MGs exhibited lesser irrigation requirements and generally a higher sale price.

\section{A Role for Geospatial Information Systems in Identifying Potential Tennessee Water- Quality Trading Markets. David C. Roberts and Christopher D. Clark, University of Ten- nessee.}

Thirty years after the passage of the Clean Water Act, more than $30 \%$ of Tennessee's assessed river and stream miles fail to meet applicable water quality standards. These impairments are increasingly attributable to nonpoint sources. A system of offset trading, where point sources are allowed to purchase emissions offsets from nonpoint sources, has been suggested as an alternative to existing regulatory approaches. This paper evaluates this suggestion for Tennessee using GIS technology. By spatially locating impaired waters, point sources, and nonpoint sources, this paper identifies those Tennessee watersheds that are most likely to support a market in emissions offsets.

Working Lands Programs: Potential Tools for Conserving Agricultural Wetlands. John $V$. Westra and Rex H. Caffey, Louisiana State University; and Jay V. Huner, University of Louisiana.

More than 500,000 acres of land in rice and crawfish production in Louisiana provide nesting, wintering, and breeding habitat for more than 100 species of waterbirds. These agricultural wetlands are critically important waterbird habitat because more than one million acres of adjacent coastal wetlands have been lost since 1950. Land planted to rice in Louisiana has decreased due to falling real prices and increasing production costs. Loss of agricultural wetlands, importation of low-cost crawfish meat, and loss of crawfish-processing facilities have negatively influenced crawfish production. Conservation payments for agricultural wetlands may mitigate potential habitat loss, benefit local wildlife, and help producers financially. 